\title{
Hydrous SiO2 in subducted oceanic crust and water transport to the core-mantle boundary
}

\section{Yanhao Lin ( $\nabla$ yhlin87@163.com )}

CARNEGIE INSTITUTION WASHINGTON https://orcid.org/0000-0003-0234-3157

\section{Qingyang Hu}

Center for High Pressure Science and Technology Advanced Research https://orcid.org/0000-0002-

2742-3017

\section{Jing Yang}

The University of Texas at Austin

\section{Yue Meng}

Carnegie Institute of Washington

\section{Yukai Zhuang}

Center for High Pressure Science and Technology Advanced Research

\section{Michael Walter}

Carnegie Institution of Science

\section{Ho-Kwang Mao}

Center for High Pressure Science and Technology Advanced Research

\section{Article}

Keywords: Stishovite, Lower Mantle Geotherm, Ultra-low Velocity Mantle Regions

Posted Date: October 1st, 2020

DOI: https://doi.org/10.21203/rs.3.rs-81103/v1

License: (c) (1) This work is licensed under a Creative Commons Attribution 4.0 International License.

Read Full License 
1 Hydrous $\mathrm{SiO}_{2}$ in subducted oceanic crust and water transport to the core2 mantle boundary

3 Yanhao Lin $^{1,2 *}$, Qingyang $\mathrm{Hu}^{1 *}$, Jing $\mathrm{Yang}^{2}$, Yue Meng ${ }^{3}$, Yukai Zhuang ${ }^{1}$, Michael J. 4 Walter $^{2 *}$, Ho-Kwang Mao ${ }^{{ }^{*}}$

$5 \quad{ }^{1}$ Center for High Pressure Science and Technology Advanced Research, Shanghai 201203, 6 People's Republic of China

$7 \quad{ }^{2}$ Earth and Planets Laboratory, Carnegie Institution for Science, Washington, DC 20015

$8{ }^{3}$ HPCAT, X-ray Science Division, Argonne National lab, Lemont, IL 60439

Subduction of oceanic lithosphere transports surface water into the mantle where it can have remarkable effects, but how much can be cycled down into the deep mantle, and potentially to the core, remains ambiguous. Recent studies show that dense $\mathrm{SiO}_{2}$ 13 in the form of stishovite, a major phase in subducted oceanic crust at depths greater 14 than $\sim 300 \mathrm{~km}$, has the potential to host and carry water into the lower mantle. We 15 investigate the hydration of stishovite and its higher-pressure polymorphs, $\mathbf{C a C l}_{2}$ 16 type $\mathrm{SiO}_{2}$ and seifertite, in experiments at pressures of 44-152 GPa and temperatures 17 of $\sim 1380-3300 \mathrm{~K}$. We quantify the water storage capacity of these dense $\mathrm{SiO}_{2}$ phases 18 at high pressure and find that water stabilizes $\mathrm{CaCl}_{2}$-type $\mathrm{SiO}_{2}$ to pressures beyond 19 the base of the mantle. We parametrize the P-T dependence of water capacity and 20 model $\mathrm{H}_{2} \mathrm{O}$ storage in $\mathrm{SiO}_{2}$ along a lower mantle geotherm. Dehydration of slab mantle in cooler slabs in the transition zone can release fluids that hydrate stishovite in oceanic crust. Hydrous $\mathrm{SiO}_{2}$ phases are stable along a geotherm and progressively dehydrate with depth, potentially causing partial melting or silica enrichment in the lower mantle. Oceanic crust can transport $\sim 0.2 \mathrm{wt} \%$ water to the core-mantle boundary region where, upon heating, it can initiate partial melting and react with the core to produce iron hydrides, providing plausible explanations for ultra-low velocity regions at the base of the mantle. 
Subduction of oceanic lithosphere drives material circulation in Earth's mantle, and provides an important conduit for the deep-water cycle and the co-evolution of the hydrosphere and solid Earth. When added to mantle rocks water can significantly affect their chemical and physical properties, including mineral phase relations ${ }^{1}$, melting temperatures ${ }^{2,3}$, electrical conductivity ${ }^{4}$ and seismic velocities ${ }^{5}$ and is implicated in deepfocus earthquakes ${ }^{6}$. Subducted lithosphere sinks gravitationally to the base of the mantle, with the oceanic crust especially providing negative buoyancy when it becomes more dense than lower mantle rocks at depths greater than $\sim 700 \mathrm{~km}^{7}$. Silica $\left(\mathrm{SiO}_{2}\right)$, as a free mineral phase, crystallizes as a major component of subducted oceanic crust $(\sim 20 \mathrm{wt} \%)$ at depths greater than about $300 \mathrm{~km}$ and undergoes several polymorphic phase changes as the crust subducts to the core-mantle boundary $(\mathrm{CMB})^{8,9}$. Stishovite, a dense $\mathrm{SiO}_{2}$ polymorph, is stable in oceanic crust from about 300 to $1500 \mathrm{~km}$, depending on temperature, where it converts to a distorted orthorhombic $\mathrm{CaCl}_{2}$-structure ${ }^{10,11}$ through a second-order displacive phase transition. The $\mathrm{CaCl}_{2}$-type phase subsequently converts to seifertite with an $\mathrm{\alpha PO}_{2}$ structure near the base of the mantle at anhydrous conditions ${ }^{12}$.

Recent work has shown that stishovite, a nominally anhydrous mineral, may host a significant amount of water in its crystal structure ${ }^{13,14}$, but the water solubility in stishovite and post-stishovite $\mathrm{SiO}_{2}$ phases remains uncertain. Here, we combine in-situ laser heating and high-pressure $\mathrm{x}$-ray diffraction measurements to constrain the phase relations and water storage capacities (i.e., water content at saturation with a hydrous fluid or melt) of stishovite, $\mathrm{CaCl}_{2}$-type silica and seifertite at $44-152 \mathrm{GPa}$ and $\sim 1380-3300 \mathrm{~K}$. We prepared starting materials comprised of $\mathrm{SiO}_{2}$ with four different water contents $(0.5,1.2,3.5$ and $15.2 \mathrm{wt} \%)$ for high-pressure experiments. Samples were heated using a double-sided laser system and held at each target temperature for $\sim 10-15$ minutes, and equations of state of $\mathrm{Pt}$ or Au were used as in situ pressure standards ${ }^{15}$. X-ray diffraction (XRD) patterns were acquired at each pressure and temperature condition and also after quenching to ambient temperature (Extended Data Fig. 1, for examples). Details of the starting compositions and experiments are described in the Methods section.

Unit cell parameters of $\mathrm{SiO}_{2}$ phases obtained from diffraction patterns are summarized in Table 1, and are compared to volumes calculated from the equation of states (EoS) of dry silica phases ${ }^{11,12,16,17}$ in Fig. 1a. At quenched ambient temperature, the volumes of stishovite, $\mathrm{CaCl}_{2}$-type $\mathrm{SiO}_{2}$ and seifertite in our experiments are generally $\sim 0.8-6.9 \%$, 64 pressures ${ }^{12,16}$, respectively. Figure 1 (b-d) shows the in-situ volumes of $\mathrm{SiO}_{2}$ at high65 temperature in this study relative to the thermal EoS of stishovite from Fisher et al. ${ }^{11}$, and 66 from the EoS from Sun et al. ${ }^{12}$ for $\mathrm{CaCl}_{2}-\mathrm{SiO}_{2}$ and seifertite. The apparent negative thermal 67 expansion in our experiments at constant pressure indicates lowering of the water storage 68 capacity in $\mathrm{SiO}_{2}$ with temperature, as has been observed for other nominally anhydrous 69 phases and is explored more fully below ${ }^{18}$. 

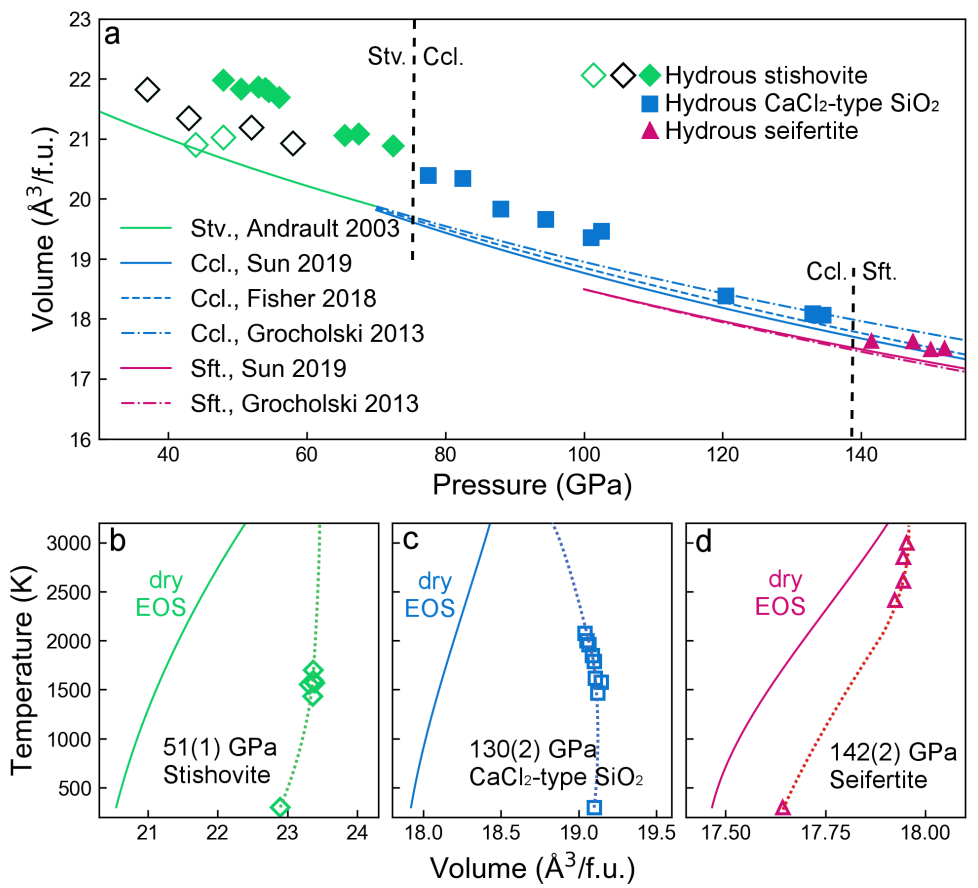

Figure 1. Measured unit cell volumes of hydrous high-pressure silica phases up to $152 \mathrm{GPa}$ and $3300 \mathrm{~K}$. (a) The solid and open symbols indicate silica volumes at water-saturated and waterunsaturated, respectively, and are compared with the equations of state for anhydrous stishovite from Andrault et al. ${ }^{16}, \mathrm{CaCl}_{2}$-type silica and seifertite from Sun et al. ${ }^{12}$, Fischer et al. ${ }^{11}$ and Grocholski et al. ${ }^{17}$ (b-d) In situ high temperature volumes of stishovite (b), $\mathrm{CaCl}_{2}$-type $\mathrm{SiO}_{2}$ (c) and seifertite (d) compared with the thermal equations of states dry silica phases (solid curves, the literature data from Andrault et al. ${ }^{16}$ and Sun et al. ${ }^{12}$ ). Temperature uncertainties are generally less than $100 \mathrm{~K}$ below $2000 \mathrm{~K}$ and are up to $150 \mathrm{~K}$ at the highest temperatures.

We establish the water storage capacity in stishovite in the $\mathrm{SiO}_{2}$-water system by observing the relationship between unit cell volume and water content in the starting composition (Fig. 2a). In principle, once a phase reaches its water saturation at constant pressure and temperature, its unit cell volume will reach a maximum and then remain constant as bulk system water content increases. We observe a linear correlation between the volume change of stishovite and the starting water contents in experiments performed at $\sim 50 \pm 6$ $\mathrm{GPa}$ and $\sim 1800 \pm 70 \mathrm{~K}$ (Fig. 2a), as given by:

$$
\left(V-V_{d r y}\right) / V_{d r y}=1.86 \times C
$$

where $V$ is the volume of hydrous stishovite, $V_{d r y}$ is the volume of anhydrous stishovite at the same pressure and $C$ is an initial water content in the starting composition. We find a maximum relative volume change of $\sim 6.5 \%$ at $\sim 3.5 \mathrm{wt} \%$ water in the starting composition, which we interpret as the storage capacity of stishovite at $\sim 50 \mathrm{GPa}$ and $\sim 1800 \mathrm{~K}$ in the $\mathrm{SiO}_{2}$-water system (Fig. 2a). Volume expansion was previously used to calibrate hydrous stishovite water contents at $1 \mathrm{bar}^{19}$ but extrapolation to higher pressure is unreliable; for example, application of the calibration in combination with the EoS of hydrous stishovite to our experiment synthesized at $53 \mathrm{GPa}\left(\mathrm{C}_{-} 188\right)$ yields $\sim 13 \mathrm{wt} \%$ water in stishovite, which is three times the water content in the starting material. However, we note the very similar 
water capacity we observe for stishovite using our method and that reported previously at $9 \mathrm{GPa}$ and $450{ }^{\circ} \mathrm{C}$ by Nisr et al. ${ }^{19}(\sim 3.2 \mathrm{wt} \%)$.

How hydrogen is incorporated into stishovite is unknown from diffraction measurements. Possible mechanisms include cation substitution via $4 \mathrm{H}^{+} \rightarrow \mathrm{Si}^{4+}$, where hydrogen bonds to oxygen $\left(\mathrm{OH}^{-}\right)$surrounding a $\mathrm{Si}$ vacancy ${ }^{14,19,20}$. Other potential mechanisms include formation of a hydride $\left(\mathrm{SiH}_{4}\right)$ and incorporation of $\mathrm{H}_{2} \mathrm{O}$, either through an inter-crystalline substitution $\left(2 \mathrm{H}^{+}+\mathrm{O}^{2-} \rightarrow 2 \mathrm{O}^{2-}+\mathrm{Si}^{4+}\right)$ or as interstitial molecular $\mathrm{H}_{2} \mathrm{O}$ in the stishovite lattice $\left(\mathrm{SiO}_{2} \cdot x \mathrm{H}_{2} \mathrm{O}\right)$, and multiple mechanisms may occur simultaneously. Of these, interstitial $\mathrm{H}_{2} \mathrm{O}$ may lead to the largest volume expansion, so as a first-order test of this mechanism we estimate the water content in stishovite using the equation of state of solid ice VII (ref. ${ }^{21}$ ). This is done by adding together the volume of anhydrous stishovite at a given pressure and the ice VII volume at the same pressure (at room temperature). Remarkably, there is a nearly one-to-one correlation between the predicted water content using ice VII and that based on our starting compositions (Fig. 2a inset). This consistency strongly suggests that the large volume changes we observe result primarily by incorporation of molecular $\mathrm{H}_{2} \mathrm{O}$ into interstitial sites (the value $x$ listed in Table 1).
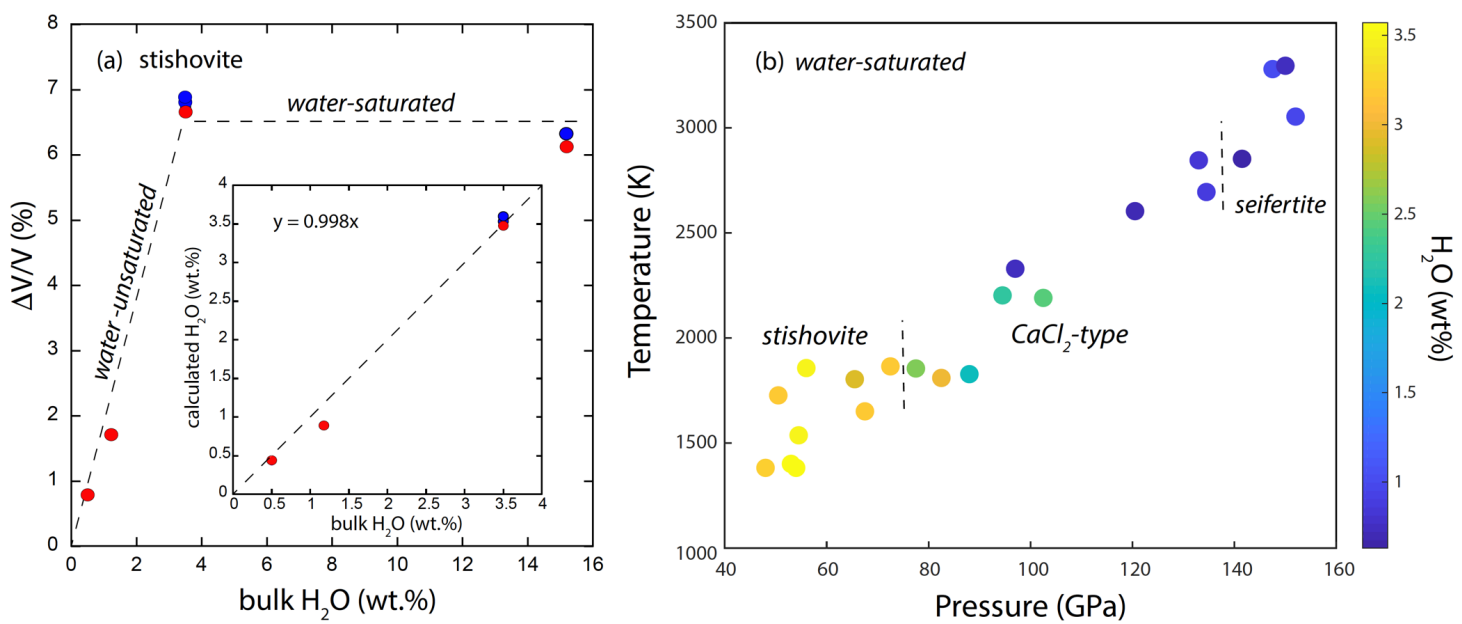

117

118

119

120

121

122

123

124

125

126

127

128

129

130

131

132

133

Figure 2. (a) Water contents in the bulk starting compositions versus measured unit cell volumes of hydrous stishovite relative to anhydrous stishovite $(\Delta V / V)$. Red symbols are experiments at $\sim 50 \pm 6 \mathrm{GPa}, 1800 \pm 70 \mathrm{~K}$ and blue symbols are experiments at other pressures and temperatures. The inset shows the water contents in the bulk starting compositions versus the water contents of hydrous stishovite calculated using the Ice VII method described in the text. (b) Pressuretemperature plot showing all experiments with 3.5 and $15.2 \mathrm{wt} \%$ water in the starting compositions (water-saturated). The symbols are colored according to the calculated water contents in the $\mathrm{SiO}_{2}$ polymorph according to the scale bar.

We conducted experiments using a starting composition with $15.2 \mathrm{wt} \% \mathrm{H}_{2} \mathrm{O}$ at $48-102$ GPa and 1380-2200 K (C_283), and 97-152 GPa and 2330-3300 K (C_154R), which we assume are all water-saturated. Estimated water storage capacities based on our Ice VII calibration are provided in Table 1 and plotted in Figure $2 \mathrm{~b}$, which shows an overall decrease in water capacity with increasing pressure and temperature. We fitted the calculated water capacity of stishovite and $\mathrm{CaCl}_{2}$-type $\mathrm{SiO}_{2}$ to a single regression assuming all experiments made using starting compositions with $3.5 \mathrm{wt} \%$ and $15.2 \mathrm{wt} \% \mathrm{H}_{2} \mathrm{O}$ were 
134 water-saturated and with pressure and temperature as independent variables, yielding the 135 equation:

$$
\mathrm{H}_{2} \mathrm{O}(\mathrm{wt} \%)=4.1(9)-0.042(7) P(\mathrm{GPa})+45(31) 1 / T(\mathrm{~K})\left(\mathrm{R}^{2}=0.85\right)
$$

Overall our limited dataset is well reproduced by this expression as indicated by the goodness of fit (Extended Data Fig. 2), although we note that the 1/T term has considerable uncertainty. As expected from Fig. 2b, the regression predicts that water capacity decreases with both pressure and temperature. Figure 3 shows the predicted water capacity of $\mathrm{SiO}_{2}$ phases along a mantle geotherm on the basis of our regression. At upper mantle pressures where stishovite first appears in oceanic crust it can hold $\sim 3.5 \mathrm{wt} \%$ water even at mantle temperatures. The P-T dependence continually reduces the water capacity to less than 1 $w t \%$ at the $\mathrm{CMB}$, as discussed below.

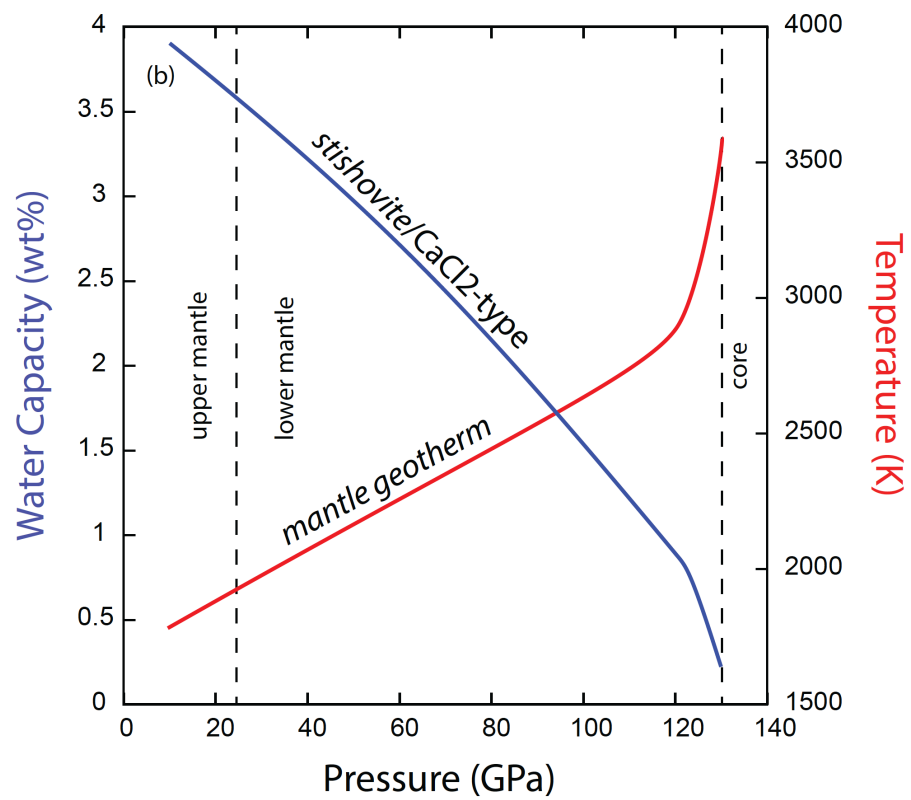

Figure 3. Modelled water capacity (blue curve) of stishovite and $\mathrm{CaCl}_{2}$-type $\mathrm{SiO}_{2}$ as a function of pressure along an idealized mantle geotherm $\left(\right.$ red $\operatorname{curve}^{22}$ ). The water capacity decreases continuously from $>3.5 \mathrm{wt} \% \mathrm{H}_{2} \mathrm{O}$ in the transition zone to $<1 \mathrm{wt} \%$ near the core mantle boundary.

The phase transition boundaries under water-saturated conditions were bracketed between stishovite and $\mathrm{CaCl}_{2}$-type $\mathrm{SiO}_{2}$ at $75 \pm 3 \mathrm{GPa}$ and $\sim 1860 \mathrm{~K}$ (C_283), and between $\mathrm{CaCl}_{2}$ type $\mathrm{SiO}_{2}$ and $\mathrm{PbO}_{2}$-type $\mathrm{SiO}_{2}$ (seifertite) at $138 \pm 4 \mathrm{GPa}$ and $\sim 2700-2850 \mathrm{~K}$ (C_154R) (Fig. 2b). The transition boundary between stishovite and $\mathrm{CaCl}_{2}$-type $\mathrm{SiO}_{2}$ is not significantly shifted from the dry silica system (e.g. $\sim 74 \mathrm{GPa}$ and $\sim 1900 \mathrm{~K}$ summarized in Fischer et al. ${ }^{11}$ ), which is consistent with an indistinguishable high water storage capacity predicted for stishovite and the $\mathrm{CaCl}_{2}$-type polymorph; for example, the calculated water content of stishovite at $65.5 \mathrm{GPa}$ and $1804 \mathrm{~K}$ and in $\mathrm{CaCl}_{2}$-type silica at $82.5 \mathrm{GPa}$ and 1810 $\mathrm{K}$ is $\sim 3 \mathrm{wt} \%$ for both. We estimate the transition to seifertite at a pressure of $\sim 140 \mathrm{GPa}$ at $\sim 3000 \mathrm{~K}$, or $\sim 20 \mathrm{GPa}$ higher than in the dry system ${ }^{12}$, consistent with a lower water content for seifertite $(<1 \mathrm{wt} \%)$ relative to $\mathrm{CaCl}_{2}$-type $\mathrm{SiO}_{2}$. 
165 In experiments where seifertite crystallized ( $>\sim 140 \mathrm{GPa})$ using the bulk composition with $16615.2 \mathrm{wt} \%$ water, we observe a new coexisting solid phase that is well indexed to silicon 167 hydride, $\mathrm{SiH}_{4}$ (Extended Data Fig. 1c). The presence of this phase, even at temperatures in 168 excess of $3000 \mathrm{~K}$, indicates that hydrides could be important in the interiors of large, wet, rocky exoplanets, and their crystallization can also be a source of oxygen. These results need to be explored more fully and are not the focus here, but we note that the stability of $\mathrm{SiH}_{4}$ can potentially provide a source of hydrogen in Earth's core.

Free silica phases are unexpected in most or all of Earth's mantle because the $\mathrm{Mg} / \mathrm{Si}$ ratio of primitive upper mantle peridotite is greater than unity $(\sim 1.1)^{23}$. Modeling of seismic velocity observations are permissive of a lower mantle composition with a $\mathrm{Mg} / \mathrm{Si}$ ratio nearer unity ${ }^{24,25}$, but even these compositions are not expected to contain a free silica phase. In contrast, oceanic crust has a low $\mathrm{Mg} / \mathrm{Si}$ ratio much less than unity and, therefore, free silica phases have the potential to host and transport water into the deep mantle in subducted slabs. However, this does not mean that water is available for transport.

Water is added to the oceanic crust through hydrothermal alteration at the mid-ocean ridge and hydration at the surface of the slab. Plate-bending at the outer rise results in fracture development in the deforming plate, with fractures penetrating through the crust and extending some $20-30 \mathrm{~km}$ into the slab mantle, allowing seawater to circulate deeply to serpentinize mantle lithosphere ${ }^{26-29}$. Dehydration of oceanic crust is very efficient beneath the volcanic front and is expected to be nearly complete at depths $<250 \mathrm{~km}^{30,31}$, shallower than the depths where stishovite first crystallizes $(\sim 300 \mathrm{~km})$. Likewise, in hotter subduction zones serpentine in the slab mantle is also expected to extensively dehydrate at depths < $\sim 250 \mathrm{~km}$ due to a depression in the dehydration phase boundaries at $\sim 6 \mathrm{GPa}$ (Extended Data Fig. 3). However, in cooler subduction zones dehydration can be avoided, and water can be transported into the transition zone hosted in post-serpentine hydrous phases (e.g. phase E, superhydrous phase B, and phase D) ${ }^{31,32}$. Estimates based on phase relations and slab thermal profiles suggest that in cooler slabs $\sim 4-5 \mathrm{wt} \%$ water can be stored in hydrated portions of mantle lithosphere 33,34 .

Silica phases provide a mechanism to transport water released from the slab in the transition zone into the lower mantle and all the way to the CMB. As slabs stagnate and heat up in the transition zone due to buoyancy and rheological effects accompanying phase changes $^{35,36}$, water may be released through dehydration of post-serpentine phases ${ }^{33,37}$ (Extended Data Fig. 3). Even without stagnation, phase relations indicate that by $\sim 1000$ $\mathrm{km}$ any water held in slab lithosphere will be released when superhydrous phase B or Phase $\mathrm{D}$ breaks down to form bridgmanite ( \pm periclase or stishovite) coexisting with a hydrous fluid or melt phase. Percolation of water-rich fluids into the adjacent oceanic crust, possibly along pre-existing fracture systems related to lithospheric hydration, creates the opportunity for hydration of stishovite. At transition zone pressures and temperatures stishovite can accommodate $\sim 3.5 \mathrm{wt} \%$ water $(\sim 0.7 \mathrm{wt} \%$ in bulk crust) and, depending on the efficiency of the fluid migration process, oceanic crust can potentially accommodate all of the released water. 
210 A simple estimate of the capacity of subducted oceanic crust to hydrate the deep mantle, 211 on the basis of silica phases in oceanic crust alone, can be made for modern Earth using an 212 average subduction rate $\left(5 \mathrm{~cm} \mathrm{yr}^{-1}\right)$, global length of subduction zones $(46,000 \mathrm{~km})$ and 213 mean crustal thickness $(6 \mathrm{~km})\left(\right.$ ref. $\left.{ }^{38}\right)$, and assuming a conservative water capacity of 214 hydrous stishovite in oceanic crust of $3 \mathrm{wt} \%$ in the transition zone. This calculation yields

$215 \sim 1.4 \times 10^{21} \mathrm{~kg}$ water, or about one ocean mass, over 4 billion years of subduction. While a 216 more precise accounting requires knowledge of the water storage capacity of all coexisting 217 phases, given that current estimates of total mantle water content are about one ocean mass 218 on the basis of geochemical arguments ${ }^{39}$, and that modeling of water transport into the deep mantle by subduction over Earth's history yields a similar value ${ }^{31}$, we find that $\mathrm{SiO}_{2}$ phases provide a quantitatively plausible explanation for hydrating the deep mantle. If the mantle currently has about one ocean mass of water ${ }^{39}$ that has been obtained through plate tectonic recycling, the implication is that the initial mantle was nearly anhydrous, perhaps owing to higher mantle temperatures in the early Earth ${ }^{40}$ resulting in near-complete early mantle dehydration; this is also consistent with isotopic data indicating more than one ocean of water at the Earth's surface in the Archean ${ }^{41,42}$.

Direct evidence for slab water release in the transition zone and uppermost lower mantle comes from inclusions in sublithospheric diamonds. Although exceedingly rare, the presence of a hydrous ringwoodite inclusion in a diamond suite from Brazil, whose provenance has been related to subducted lithosphere, provides direct evidence for local hydration $^{43}$. Further, boron-, oxygen, carbon and nitrogen isotopes of diamonds and their inclusions derived from the base of the transition zone and uppermost lower mantle indicate a direct role for aqueous fluids associated with seawater serpentinization near the surface and eventual dehydration of slab lithosphere at the base of the transition zone ${ }^{44,45}$.

A link between dehydration of slab mantle in cooler subducting slabs in the transition zone and deep focus earthquakes has been postulated ${ }^{46}$, and given its propensity for hydration, stishovite could play a role in whichever of the competing mechanism leads to deep seismicity ${ }^{47}$. The process depicted in Fig. 4, where stishovite in oceanic crust is hydrated by the release of mantle fluids along pre-existing slab faults and cracks, is accompanied by a substantial positive volume change. For example, fully hydrating stishovite in oceanic crust at $20 \mathrm{GPa}$ results in an $\sim 6.5 \%$ volume increase, which, when ignoring partitioning with other anhydrous minerals, results in an $\sim 1.3 \%$ volume increase in the whole rock. This very large, positive volume change would create $\sim 5 \mathrm{GPa}$ overpressure above the hydrostatic load at $20 \mathrm{GPa}$, locally creating high compressive stresses. The role that stishovite hydration and expansion might play in deep focus earthquake mechanisms requires further investigation.

Hydration of stishovite in the transition zone provides a conduit for water to the deep lower mantle and core. We note that other hydrous phases can also crystallize in oceanic crust at high pressures, including Phase $\mathrm{D}$, Phase $\mathrm{H}$ and $\delta$-AlOOH (ref. ${ }^{18}$ ), but these phases would only stabilize after saturation of primary silica phases with water and other coexisting nominally anhydrous phases in oceanic crust (Extended Data Fig. 4). Perhaps more importantly, these phases have a much lower temperature stability ${ }^{18,48}$. Figure 3 shows that stishovite will enter the lower mantle with $>3 \mathrm{wt} \%$ water even along a mantle geotherm, 
but will progressively dehydrate (as $\mathrm{CaCl}_{2}$-type $\mathrm{SiO}_{2}$ at $>75 \mathrm{GPa}$ ) as it transits the mantle to the core mantle boundary region. Hydrous fluids or melts released in this way may percolate away from the slab into the ambient mantle resulting in crystallization of aluminous Phase $\mathrm{H}$ (Extended Data Fig. 4), but at temperatures of the mantle geotherm a hydrous partial melt is predicted on the basis of experimental phase relations ${ }^{48}$. While we have no compositional information about these fluids, it is likely that they will be supercritical solutions at these high pressures and temperatures such that they could enrich the lower mantle locally in a dissolved silica component, converting ferropericlase to bridgmanite, and possibly stabilizing a free, and hydrated, silica phase that is stable at mantle temperatures.

Upon arrival just above the $\mathrm{CMB}(\sim 120 \mathrm{GPa}) \mathrm{CaCl}_{2}$-type $\mathrm{SiO}_{2}$ may carry about $0.8 \mathrm{wt} \%$ water $(\sim 0.2 \mathrm{wt} \%$ in bulk crust), but the superadiabatic temperature gradient above the core mantle boundary ${ }^{49}$ would induce nearly complete dehydration $(<0.04 \%$ in bulk crust) as crust sinks to the CMB (Fig. 4). Release of water in this region may generate partial melting due to the effect of water on lowering the solidus of peridotite by hundreds of degrees ${ }^{50}$ and changing the mineral assemblage ${ }^{51}$. Reaction of released water with the iron-metal outer core may also crystallize new high-pressure phases (e.g., $\left.\mathrm{FeO}_{2} \mathrm{H}_{x}, \mathrm{FeH}_{5}\right)^{52-56}$. Production of partial melt and iron hydride phases have both been shown to provide plausible explanations for the observed seismic anisotropy ${ }^{57}$ and anomalously slow P-wave velocities ${ }^{58}$ at the base of Earth's mantle (Fig. 4). Water-bearing fluids released at the core -mantle boundary could also hydrate $\mathrm{SiO}_{2}$ expelled from the core and accumulated at the CMB before buoyant diapiric upwelling ${ }^{59}$. Similarly, water expelled from the slab in the lower mantle may be incorporated into silica diapirs as they rise from the CMB to the midor upper-lower mantle. Hydration of silica phases in subducted oceanic crust and their unparalleled capacity to host significant amounts of water even at high mantle temperatures provides a unique mechanism for transport and storage of water to the deepest mantle.

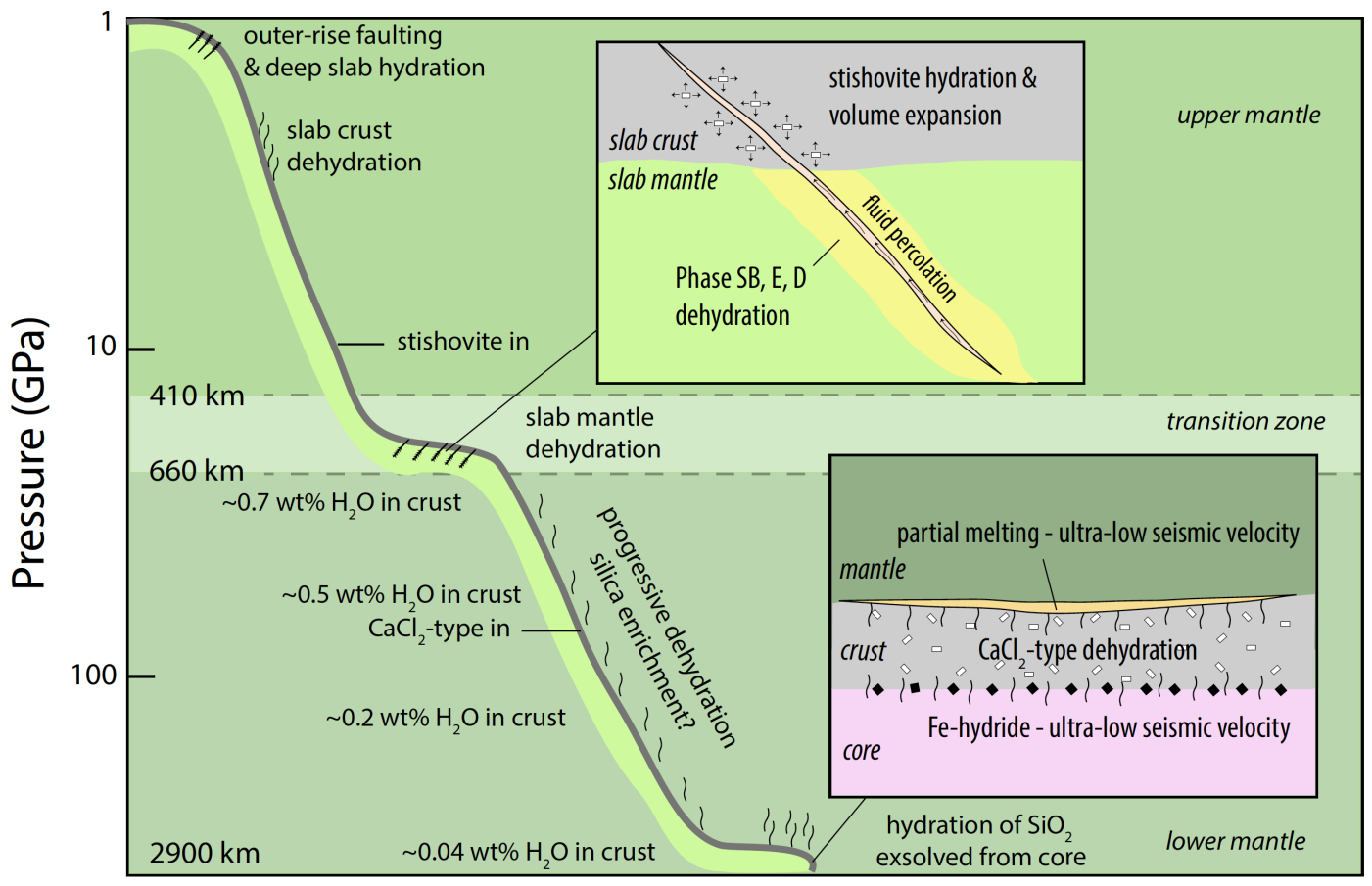


284 Figure 4. A schematic model for transport of water into the deep mantle in hydrous silica phases. 285 Water is added to slab crust and mantle near the surface through interaction of seawater with the crust and through faults and cracks in the lithosphere formed by slab bending at the outer rise. Oceanic crust extensively dehydrates at $<200 \mathrm{~km}$ depth, but slab mantle can carry water into the transition zone in hydrous phases in cooler slabs. Dehydration of hydrous phases in slab mantle in the transition zone generates hydrous fluids that migrate along fractures to the oceanic crust where they hydrate stishovite $(\sim 3.5 \mathrm{wt} \%$ water $)$. Stishovite transports water into the lower mantle where it converts to $\mathrm{CaCl}_{2}$-type $\mathrm{SiO}_{2}$, and the water capacity of these phases decreases continuously as the slab transits the lower mantle, potentially releasing hydrous fluids to the mantle that may cause melting and potentially enrich the mantle in silica. The rapid increase in temperature near the coremantle boundary may release a pulse of water that can induce partial melting ${ }^{50}$ and/or the crystallization of iron-hydride phases (e.g., $\left.\mathrm{FeO}_{2} \mathrm{H}_{x}, \mathrm{FeH}_{5}\right)^{52-56}$ upon reaction with the metallic iron core, potentially leading to regions of ultra-low seismic velocity. Fluid release may also hydrate silica-rich domains at the core-mantle boundary formed through exsolution from the core. 
1. Inoue, $\mathrm{T}$. Effect of water on melting phase relations and melt composition in the system $\mathrm{Mg}_{2} \mathrm{SiO}_{4}-\mathrm{MgSiO}_{3}-\mathrm{H}_{2} \mathrm{O}$ up to $15 \mathrm{GPa}$. Phys. Earth Planet. Inter. 85, 237263 (1994).

2. Wang, J., Takahashi, E., Xiong, X., Chen, L., Li, L., Suzuki, T. \& Walter, M. J. The water-saturated solidus and second critical endpoint of peridotite: Implications for magma genesis within the mantle wedge. J. Geophys. Res. Solid Earth 125, e2020JB019452 (2020).

3. Schmandt, B., Jacobsen, S. D., Becker, T. W., Liu, Z. \& Dueker, K. G. Dehydration melting at the top of the lower mantle. Science 344, 1265-1268 (2014).

4. Yoshino, T., Matsuzaki, T., Yamashita, S. \& Katsura, T. Hydrous olivine unable to account for conductivity anomaly at the top of the asthenosphere. Nature 443, 973976 (2006).

5. Zhang, J. \& Bass, J. D. Sound velocities of olivine at high pressures and temperatures and the composition of Earth's upper mantle. Geophys. Res. Lett. 43, 9611-9618 (2016).

6. Meade, C. \& Jeanloz, R. Deep-focus earthquakes and recycling of water into the Earth's mantle. Science 252, 68-72 (1991).

7. Hirose, K., Fei, Y., Ma, Y. \& Mao, H. The fate of subducted basaltic crust in the Earth's lower mantle. Nature 397, 53-56 (1999).

8. Perrillat, J. -P. et al. Phase transformations of subducted basaltic crust in the upmost lower mantle. Phys. Earth Planet. Inter. 157, 139-149 (2006).

9. Walter, M. et al. Deep mantle cycling of oceanic crust: Evidence from diamonds and their mineral inclusions. Science 334, 54-57 (2011).

10. Kingma, K. J., Cohen, R. E., Russell, J. \& Mao, H. K. Transformation of stishovite to a denser phase at lower-mantle pressures. Nature 374, 243-245 (1995).

11. Fischer, R. A. et al. Equations of state and phase boundary for stishovite and $\mathrm{CaCl}_{2}-$ type $\mathrm{SiO}_{2}$. Am. Mineral. 103, 792-802 (2018).

12. Sun, N., Shi, W., Mao, Z., Zhou, C. \& Prakapenka, V. B. High pressure-temperature study on the thermal equations of state of seifertite and $\mathrm{CaCl}_{2}$-type $\mathrm{SiO}_{2}$. J. Geophys. Res. 124, 12620-12630 (2019).

13. Lin, Y., Hu, Q., Meng, Y., Walter, M. \& Mao, H.-K. Evidence for the stability of ultrahydrous stishovite in Earth's lower mantle. Proc. Natl Acad. Sci. USA 117, 184-189 (2020).

14. Nisr, C. et al. Large $\mathrm{H}_{2} \mathrm{O}$ solubility in dense silica and its implications for the interiors of water-rich planets. Proc. Natl Acad. Sci. USA 117, 9747-9754 (2020).

15. Fei, Y. et al. Toward an internally consistent pressure scale. Proc. Natl Acad. Sci. USA 104, 9182-9186 (2007).

16. Andrault, D. M., Angel, R. J., Mosenfelder, J. L. \& Bihan, T. L. Equation of state of stishovite to lower mantle pressures. Am. Mineral. 88, 301-307 (2003).

17. Grocholski, B., Shim, S. -H. \& Prakapenka, V. B. Stability, metastability, and elastic properties of a dense silica polymorph, seifertite. J. Geophys. Res. Solid Earth 118, 4745-4757 (2013).

18. Ohtani, E. Hydrous minerals and the storage of water in the deep mantle. Chem. Geol. 418, 6-15 (2015).

19. Nisr, C., Shim, S. H., Leinenweber, K. \& Chizmeshya, A. Raman spectroscopy of 
water-rich stishovite and dense high-pressure silica up to $55 \mathrm{GPa}$. Am. Mineral. 102, 2180-2189 (2017).

20. Spektor, K. et al. Ultrahydrous stishovite from high-pressure hydrothermal treatment of $\mathrm{SiO}_{2}$. Proc. Natl Acad. Sci. USA 108(52), 20918-20922 (2011).

21. Wolanin, E., Pruzan, Ph., Chervin, J. C., Canny, B. \& Gauthier, M. Equation of state of ice VII up to 106 GPa. Phys. Rev. B 56, 5781-5785 (1997).

22. Katsura, T., Yoneda, A., Yamazaki, D., Yoshino, T. \& Ito, E. Adiabatic temperature profile in the mantle. Phys. Earth Planet. Inter. 183, 212-218 (2010).

23. McDonough, W. F. \& Sun, S. -S. The composition of the Earth. Chem. Geol. 120, 223-253 (1995).

24. Matas, J., Bass, J., Ricard, Y., Mattern, E. \& Bukowinski, M. S. T. On the bulk composition of the lower mantle: Predictions and limitations from generalized inversion of radial seismic profiles. Geophys. J. Int. 170, 764-780 (2007).

25. Murakami, M., Ohishi, Y., Hirao, N. \& Hirose, K. A perovskitic lower mantle inferred from high-pressure, high-temperature sound velocity data. Nature $\mathbf{4 8 5}$, 90 94 (2012).

26. Hatakeyama, K., Katayama, I., Hirauchi, K. \& Michibayashi, K. Mantle hydration along outer-rise faults inferred from serpentinite permeability. Sci. Rep. 7, 13870 (2017).

27. Faccenda, M. Water in the slab: A trilogy. Tectonophysics 614, 1-30 (2014).

28. Alt, J. C. et al. The role of serpentinites in cycling of carbon and sulfur: seafloor serpentinization and subduction metamorphism. Lithos 178, 40-54 (2013).

29. Boschi, C. et al. Serpentinization of mantle peridotites along an uplifted lithospheric section, Mid Atlantic Ridge at $11^{\circ}$ N. Lithos 178, 3-23 (2013).

30. Plank, T., Kelley, K. A., Zimmer, M. M., Hauri, E. H. \& Wallace, P. J. Why do mafic arc magmas contain $\sim 4 \mathrm{wt} \%$ water on average? Earth Planet. Sci. Lett. 364, 168-179 (2013).

31. Van Keken, P. E., Hacker, B. R. \& Syracuse, E. M. Subduction factory. 4. Depthdependent flux of $\mathrm{H}_{2} \mathrm{O}$ from subducting slabs worldwide. J. Geophys. Res. Solid Earth 116, B01401 (2011).

32. Poli, S. \& Schmidt, M. W. Petrology of subducted slabs. Annu. Rev. Earth Planet. Sci. 30, 207-235 (2002).

33. Komabayashi, T. \& Omori, S. Internally consistent thermodynamic data set for dense hydrous magnesium silicates up to $35 \mathrm{GPa}, 1600{ }^{\circ} \mathrm{C}$ : Implications for water circulation in the Earth's deep mantle. Phys. Earth Planet. Inter. 156, 73-90 (2006).

34. Iwamori, $\mathrm{H}$. Phase relations of peridotites under $\mathrm{H}_{2} \mathrm{O}$-saturated conditions and ability of subducting plates for transportation of $\mathrm{H}_{2} \mathrm{O}$. Earth Planet. Sci. Lett. 227, 57-71 (2004).

35. Bina, C. R. Patterns of deep seismicity reflect buoyancy stresses due to phase transitions. Geophys. Res. Lett. 24, 3301-3304 (1997).

36. Billen, M. Modeling the dynamics of subducting slabs. Annu. Rev. Earth Planet. Sci. 36, 325-56 (2008).

37. Komabayashi, T., Omori S. \& Maruyama, S. Petrogenetic grid in the system MgO$\mathrm{SiO}_{2}-\mathrm{H}_{2} \mathrm{O}$ up to $30 \mathrm{GPa}, 1600{ }^{\circ} \mathrm{C}$ : Applications to hydrous peridotite subducting into the Earth's deep interior. J. Geophys. Res. 109, B03206 (2004).

38. Panero, W. R., Benedetti, L. R. \& Jeanloz, R. Transport of water into the lower 
mantle: Role of stishovite. J. Geophys. Res. 108(B1), 2039 (2003).

39. Hirschmann, M. M. \& Dasgupta, R. The H/C ratios of Earth's near-surface and deep reservoirs, and consequences for deep Earth volatile cycles. Chem. Geol. 262, 4-16 (2009).

40. Herzberg, C., Condie, K. \& Korenaga, J. Thermal history of the Earth and its petrological expression. Earth Planet. Sci. Lett. 292, 79-88 (2010).

41. Pope, E. C., Bird, D. K. \& Rosing, M. T. Isotope composition and volume of Earth's early oceans. Proc. Natl Acad. Sci. USA 109, 4371-4376 (2012).

42. Johnson, B. W. \& Wing, B. A. Limited Archaean continental emergence reflected in an early Archaean ${ }^{18} \mathrm{O}$-enriched ocean. Nat. Geosci. 13, 243-248 (2020).

43. Pearson, D. G. et al. Hydrous mantle transition zone indicated by ringwoodite included within diamond. Nature 507, 221-224 (2014).

44. Smith, E. M. et al. Blue boron-bearing diamonds from Earth's lower mantle. Nature 560, 84-87 (2018).

45. Regier, M. E., Pearson, D. G., Stachel, T., Luth, R. W., Stern, R. A. \& Harris, J. W. The lithospheric-to-lower-mantle carbon cycle recorded in superdeep diamonds. Nature 585, 234-238 (2020).

46. Omori, S., Komabayashi, T. \& Maruyama, S. Dehydration and earthquakes in the subducting slab: empirical link in intermediate and deep seismic zones. Phys. Earth Planet. Inter. 146 (1-2), 297-311 (2004).

47. Zhan, Z. Mechanisms and implications of deep earthquakes. Annu. Rev. Earth Planet. Sci. 48, 147-174 (2020).

48. Walter, M. J. et al. The stability of hydrous silicates in Earth's lower mantle: Experimental constraints from the systems $\mathrm{MgO}-\mathrm{SiO}_{2}-\mathrm{H}_{2} \mathrm{O}$ and $\mathrm{MgO}-\mathrm{Al}_{2} \mathrm{O}_{3}-$ $\mathrm{SiO}_{2}-\mathrm{H}_{2}$ O. Chem. Geol. 418, 16-29 (2015).

49. Kuwayama, Y. et al. Equation of State of Liquid Iron under Extreme Conditions. Phys. Rev. Lett. 124, 165701 (2020).

50. Nomura, R., Hirose, K., Uesugi, K., Ohishi, Y., Tsuchiyama, A., Miyake, A. \& Ueno, Y. Low core-mantle boundary temperature inferred from the solidus of pyrolite. Science 343, 522-525 (2014).

51. Hu, Q. et al. Mineralogy of the deep lower mantle in the presence of $\mathrm{H}_{2} \mathrm{O}$. Natl. Sci. Rev. https://doi.org/10.1093/nsr/nwaa098.

52. $\mathrm{Hu}, \mathrm{Q}$. et al. $\mathrm{FeO}_{2}$ and $\mathrm{FeOOH}$ under deep lower-mantle conditions and Earth's oxygen-hydrogen cycles. Nature 534, 241-244 (2016).

53. Nishi, M., Kuwayama, Y., Tsuchiya, J. \& Tsuchiya, T. The pyrite-type highpressure form of FeOOH. Nature 547, 205-208 (2017).

54. Liu, J. et al. Hydrogen-bearing iron peroxide and the origin of ultralow-velocity zones. Nature 551, 494-497 (2017).

55. Mao, H. -K. et al. When water meets iron at Earth's core-mantle boundary. Natl. Sci. Rev. 4(6), 870-878 (2017).

56. Pépin, C. M., Geneste, G., Dewaele, A., Mezouar, M. \& Loubeyre, P. Synthesis of $\mathrm{FeH}_{5}$ : A layered structure with atomic hydrogen slabs. Science 357, 382-385 (2017).

57. Kendall, J. M. \& Silver, P. Constraints from seismic anisotropy in the lowermost mantle. Nature 381, 409-412 (1996).

58. Williams, Q. \& Garnero, E. Seismic evidence for partial melt at the base of Earth's 
mantle. Science 273, 1528-1530 (1996). 59. Helffrich, G., Ballmer, M. D. \& Hirose, K. Core-exsolved $\mathrm{SiO}_{2}$ dispersal in the Earth's mantle. J. Geophys. Res. Solid Earth 123, 176-188 (2018). 
441 Table 1. Summary of experimental results.

\begin{tabular}{|c|c|c|c|c|c|c|c|c|c|c|c|c|c|c|c|}
\hline \multirow[b]{2}{*}{ Exp. } & \multirow{2}{*}{$\begin{array}{c}\text { Water at } \\
\text { starting } \\
\text { comp. } \\
\text { (wt. \%) }\end{array}$} & \multicolumn{2}{|c|}{$\mathrm{T}(\mathrm{K})$} & \multirow[b]{2}{*}{$a(\AA)$} & \multirow[b]{2}{*}{$b(\AA)$} & \multirow[b]{2}{*}{$c(\AA)$} & \multirow[b]{2}{*}{$\begin{array}{l}V\left(\AA^{3}\right) / \\
\text { f.u. }\end{array}$} & \multirow[b]{2}{*}{$\begin{array}{c}1 \text { Sigma } \\
\left(\AA^{3}\right)\end{array}$} & \multirow[b]{2}{*}{$\begin{array}{l}\mathrm{P}(\mathrm{GPa}) / \\
\mathrm{Pt} \text { or } \mathrm{Au}\end{array}$} & \multirow[b]{2}{*}{$\begin{array}{c}V(\text { dry }) \\
\left(\AA^{3}\right)\end{array}$} & \multirow[b]{2}{*}{$\begin{array}{c}\Delta V\left(\AA^{3}\right) \\
\left(=\mathrm{V}_{\text {wet }}-\mathrm{V}_{\mathrm{dry}}\right)\end{array}$} & \multirow[b]{2}{*}{$\begin{array}{c}\Delta V / V \\
(\%)\end{array}$} & \multirow[b]{2}{*}{$\begin{array}{c}V(\text { Ice } \\
\text { VII) }\left(\AA^{3}\right)\end{array}$} & \multirow[b]{2}{*}{$\begin{array}{c}x \\
\left(\mathrm{H}_{2} \mathrm{O}\right)\end{array}$} & \multirow{2}{*}{$\begin{array}{c}C^{*} \\
\left(\mathrm{H}_{2} \mathrm{O},\right. \\
\text { wt.\%) }\end{array}$} \\
\hline & & $\begin{array}{c}T_{-} L H \\
(\mathrm{~K})\end{array}$ & $\begin{array}{c}\text { T_XRD } \\
(\mathrm{K})\end{array}$ & & & & & & & & & & & & \\
\hline
\end{tabular}

S_241 $\left[97 \mathrm{~mol} . \% \mathrm{SiO}_{2}+3 \mathrm{~mol} . \%\right.$ Silic acid + Pt black $]$

Stishovite

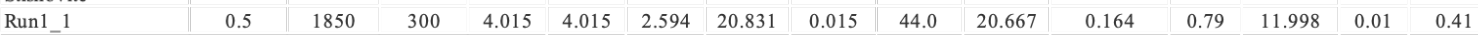

S_242 $\left[93 \mathrm{~mol} . \% \mathrm{SiO}_{2}+7 \mathrm{~mol} \%\right.$ Silic acid + Pt black $]$

Stishovite

$\begin{array}{llllllllllllllll}\text { Runl_1 } & 1.2 & 1850 & 300 & 4.020 & 4.020 & 2.602 & 21.020 & 0.018 & 48.0 & 20.667 & 0.353 & 1.71 & 11.736 & 0.03 & 0.89\end{array}$

C_ $188\left[75 \mathrm{~mol} . \% \mathrm{SiO}_{2}+25 \mathrm{~mol} . \%\right.$ Silic acid + Pt black $]$

$\begin{array}{llllllllllllllll}\text { Stishovite } & 1401 & 300 & 4.078 & 4.078 & 2.629 & 21.864 & 0.014 & 53.0 & 20.468 & 1.395 & 6.82 & 11.431 & 0.12 & 3.53 \\ \text { Run1 5 } & 14.53\end{array}$

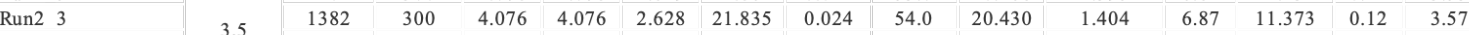

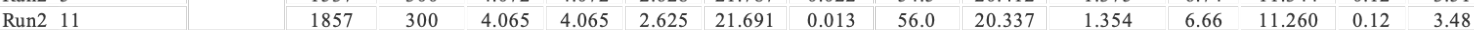

C 283 [Silic acid $+\mathrm{Au}]$

Stishovite

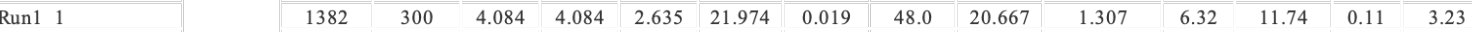

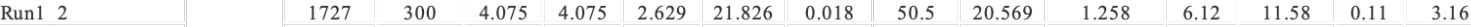

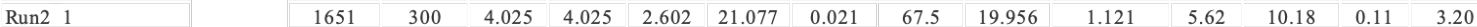

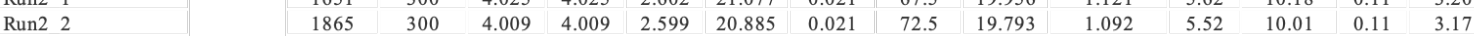

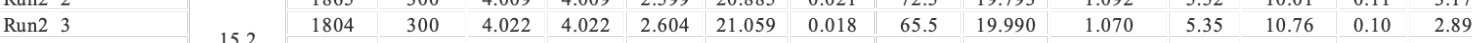

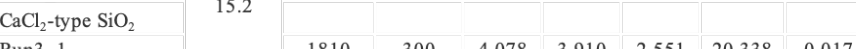

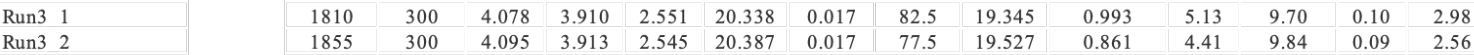

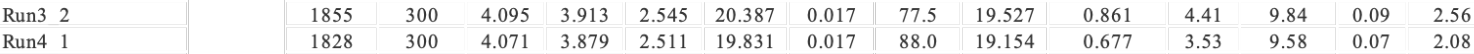

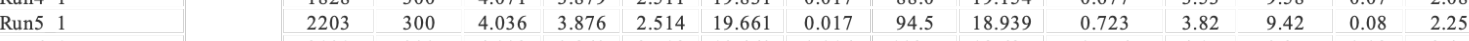

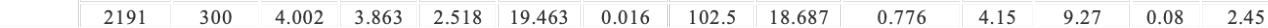

C 154 R [Silic acid + Pt black]

$\mathrm{CaCl}_{2}$-type $\mathrm{SiO}_{2}$

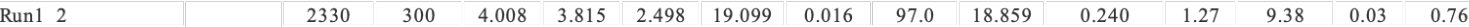

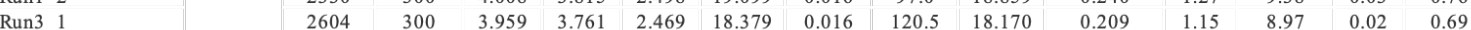

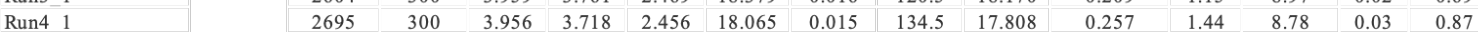

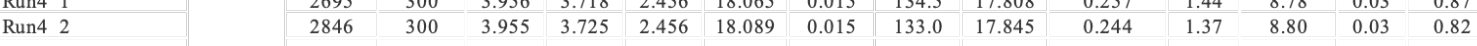

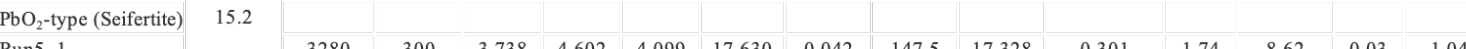

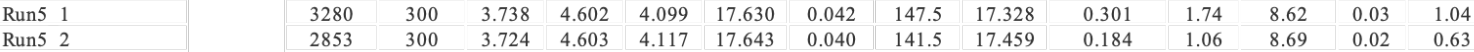

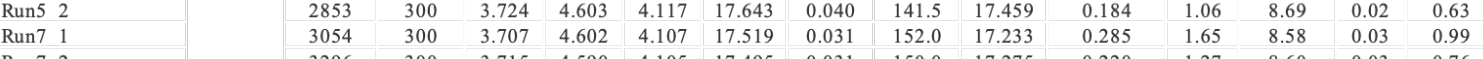

$\begin{array}{lllllllllll}\text { Run7 } 2 & 3296 & 300 & 3.715 & 4.590 & 4.105 & 17.495 & 0.031 & 150.0 & 17.275 & 0.220\end{array}$

T LH, the aim temperature before temperature quenched; T XRD, the room temperature when all XRD shown here were collected;

$\mathrm{T}$, temperature; Temperature errors are generally below $100 \mathrm{~K}$ at the aim temperature lower than $2000 \mathrm{~K}$ and are up to $150 \mathrm{~K}$ at the highest temperature achieved; $\mathrm{P}$, pressure the pressure is shown by the Pt or Au calibration ${ }^{15}$;

$V$ (dry) is calculated at the relative pressure and room temperature from Andrault et al.$^{16}$ for stishovite and Sun et al. ${ }^{12}$ for $\mathrm{CaCl}_{2}$-type and $\mathrm{PbO}_{2}$-type silica phases;

442 $C^{*}$, water concentration is calculated based on a proportional relation between the volume of ice VII (ref. 21) and the volume change $(\Delta V)$ at the same pressures; $x$ represents water content in $\mathrm{SiO}_{2} \cdot x \mathrm{H}_{2} \mathrm{O}$.

443 


\section{Methods}

445 Starting materials and experimental design. The starting compositions were mixtures 446 of amorphous $\mathrm{SiO}_{2}(1 \mu \mathrm{m}$ grain size, purity $99.999 \%)$ and silic acid $\left(\mathrm{SiO}_{2} \cdot 0.6 \mathrm{H}_{2} \mathrm{O}, 15.2\right.$ $447 \mathrm{wt} \%$ water) in different proportions (Table 1). About $10 \mathrm{wt} \%$ amorphous Pt or Au powder 448 was added to the mixture for infrared laser absorption in laser heating experiment. The 449 mixtures were ground for 4-6 hours.

The first type of starting material was only silic acid with $\sim 15.2 \mathrm{wt} \% \mathrm{H}_{2} \mathrm{O}$ (the two experiments: C_283 and C_154R). In the experiment C_283, the sample was loaded in a $100 \mu \mathrm{m}$ diameter hole in a rhenium gasket indented by diamond anvils with $200 \mu \mathrm{m}$ diameter culet. As for $\mathrm{C}_{-} 154 \mathrm{R}$, the sample was loaded in a $45 \mu \mathrm{m}$ diameter hole in a rhenium gasket indented by diamond anvils with $90 \mu \mathrm{m}$ diameter culet beveled from 400 $\mu \mathrm{m}$ culet. The second type of starting materials was a mixture of amorphous $\mathrm{SiO}_{2}$ and silic acid with the different target water contents $(0.5 \mathrm{wt} \%$ (S_241), $1.2 \mathrm{wt} \%$ (S_242) and 3.5 wt\% (C_188)). Each sample was respectively loaded in a $120 \mu \mathrm{m}$ diameter hole in a rhenium gasket indented by diamond anvils with $250 \mu \mathrm{m}$ diameter culet. Except the sample C_283 with Au powder, the other four samples were mixed with Pt black. Pressures were determined before and after heating by the self-consistent equation of states (EOS) of the doped $\mathrm{Pt}$ or $\mathrm{Au}^{15}$, and the error bar of calibrated pressure is estimated to be of the order 1 to $2 \mathrm{GPa}$.

Samples were heated in a double-sided laser-heated diamond-anvil cell (DAC) and examined in situ at high pressures and temperatures by synchrotron x-ray powder diffraction at High Pressure Collaborative Access Team (HPCAT) of the Advanced Photon Source, Argonne National Laboratory ${ }^{60}$ and at the BL15U1 beamline, Shanghai Synchrotron Radiation Facility (SSRF) in China ${ }^{61}$. The X-ray beam size was $2.9 \times 5.4 \mu \mathrm{m}^{2}$ with a wavelength of $0.4066 \AA$ at HPCAT and was $1.0 \times 3.0 \mu \mathrm{m}^{2}$ with a wavelength of $0.6199 \AA$ at SSRF. For laser heating, the diameter of a laser heating spot was up to $\sim 30 \mu \mathrm{m}$ at $\sim 3300 \mathrm{~K}$ in the flat top area created with a focused yttrium lithium fluoride laser using a double-sided heating technique that minimizes both radial and axial temperature gradients. Temperatures were determined by fitting the thermal radiation from the central portion of the heated spot to the Planck radiation function ${ }^{60,61}$.

Data availability The authors declare that all relevant data supporting this study are available within the paper or available on request from the corresponding authors.

\section{References}

60. Meng, Y., Shen, G. \& Mao, H. K. Double-sided laser heating system at HPCAT for in situ x-ray diffraction at high pressures and high temperatures. J. Phys. Condens. Matter. 18, S1097-S1103 (2006).

61. Yuan, H. \& Zhang, L. In situ determination of crystal structure and chemistry of minerals at Earth's deep lower mantle conditions. Matter. Radiat. at Extremes. 2, $117-128$ (2017). 


\section{Acknowledgements}

489 We acknowledge Jinfu Shu for experimental assistance. This work was performed at 490 HPCAT (Sector 16), Advanced Photon Source (APS), Argonne National 491 Laboratory. HPCAT operations are supported by DOE-NNSA's Office of Experimental 492 Sciences. The Advanced Photon Source is a U.S. Department of Energy (DOE) Office of 493 Science User Facility operated for the DOE Office of Science by Argonne National 494 Laboratory under Contract No. DE-AC02-06CH11357. XRD measurements were 495 performed at the 16ID-B of HPCAT, APS, ANL. Part of the experiment was performed at 496 the BL15U1 beamline, Shanghai Synchrotron Radiation Facility in China. Y.L. and H.497 k.M. are supported by NSF Grant EAR-1722515. Y.L. is supported by Carnegie Science 498 Rapid Awards Seed Grant. The Center for High Pressure Science and Technology 499 Advanced Research is supported by National Science Foundation of China (Grants 500 U1530402 and U1930401).

501

502 Author Contributions

503 Y.L., Q.H., M.J.W. and H.-k.M. designed the research; Y.L., J.Y., M.J.W. and Y.M. 504 performed experiments; Q.H., Y.L., M.J.W. and H.-k.M. analyzed data; and Y.L., Q.H and 505 M.J.W. wrote the paper with input from all authors. Y.L., Q.H., M.J.W. and H.-k.M. 506 contributed equally to this work.

507

508 Competing interests

509 The authors declare no competing interests.

510

511 Additional information

512 Correspondence and requests for materials should be addressed to Y.L. 513 (yhlin@carnegiescience.edu), Q.H. $\quad$ (qingyang.hu@hpstar.ac.cn), $\quad$ M.J.W.

514 (mwalter@carnegiescience.edu) or H.-K.M. (maohk@hpstar.ac.cn).

515 Reprints and permissions information is available online at www.nature.com/reprints. 


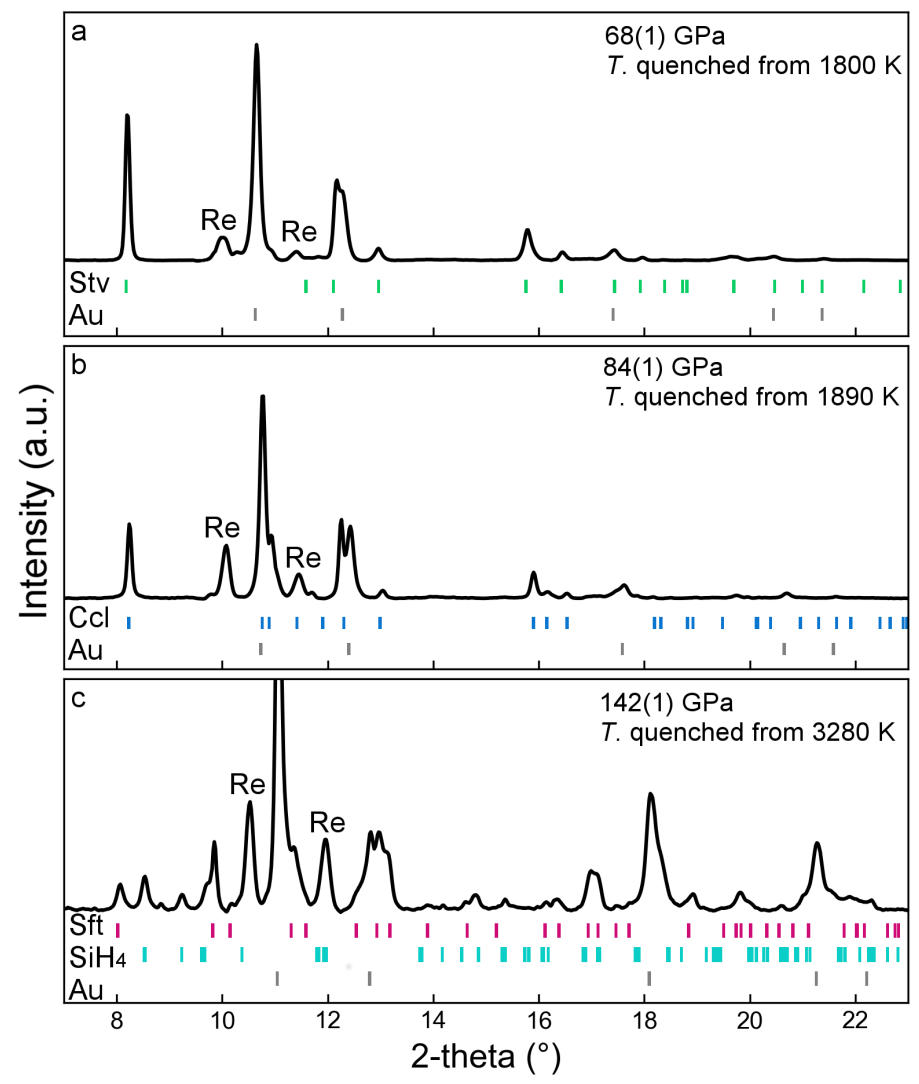

517

518 Extended Data Fig. 1 | Representative X-ray diffraction patterns at 68, 84 and $142 \mathrm{GPa}$

519 (Au pressures), $300 \mathrm{~K}$ after laser heating. Green, blue and red ticks represent the calculated 520 diffraction peaks for water-bearing stishovite (a), $\mathrm{CaCl}_{2}$-type $\mathrm{SiO}_{2}$ (b) and seifertite (c) 521 (details in Table 1), respectively. In addition, a $\mathrm{SiH}_{4}$ phase is confirmed as well at $142 \mathrm{GPa}$ 522 (c). Data were acquired using an X-ray wavelength of $0.4066 \AA$. Stv $=$ stishovite, $\mathrm{Ccl}=$ $523 \mathrm{CaCl}_{2}$-type $\mathrm{SiO}_{2}, \mathrm{Sft}=$ seifertite. 


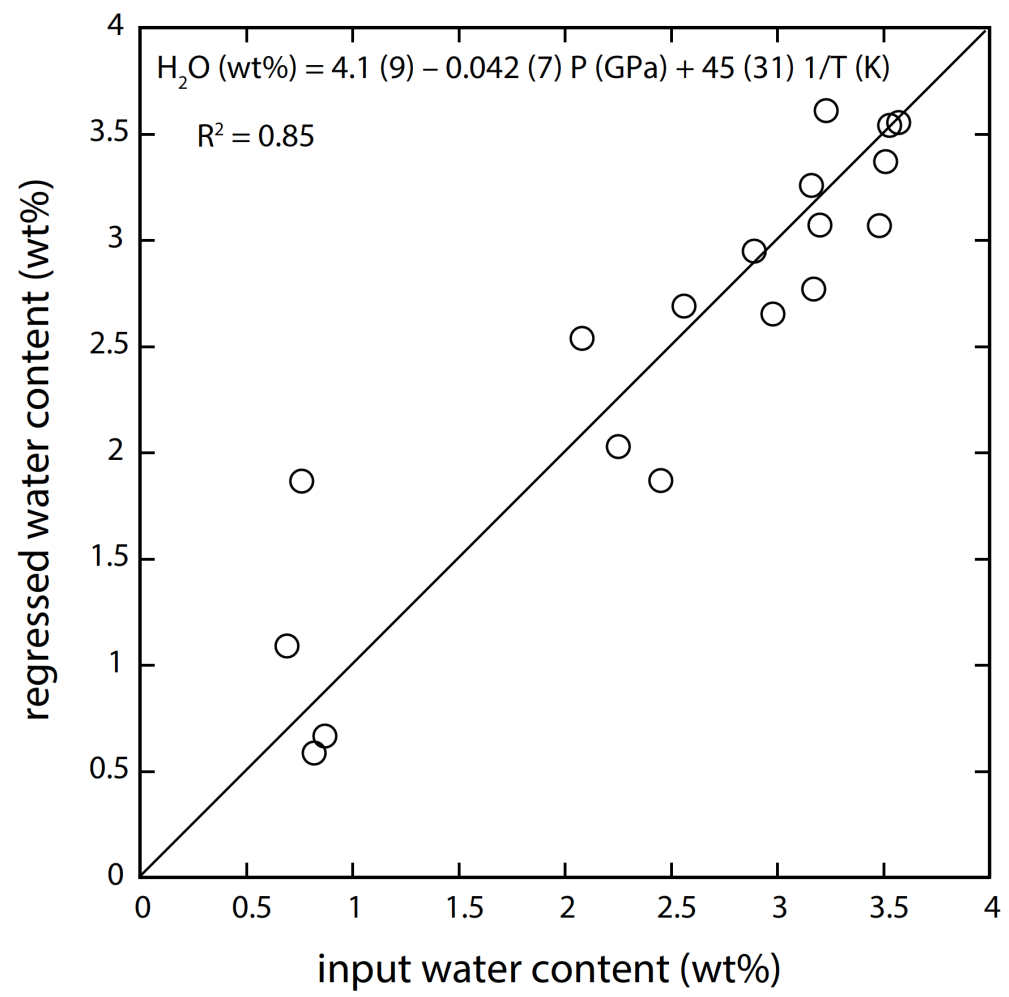

527 Extended Data Fig. 2 Diagram showing the regressed water content and the calculated 528 water content in stishovite and $\mathrm{CaCl}_{2}$-type $\mathrm{SiO}_{2}$ in all water-saturated experiments. The 529 line shows an ideal 1:1 correspondence. 


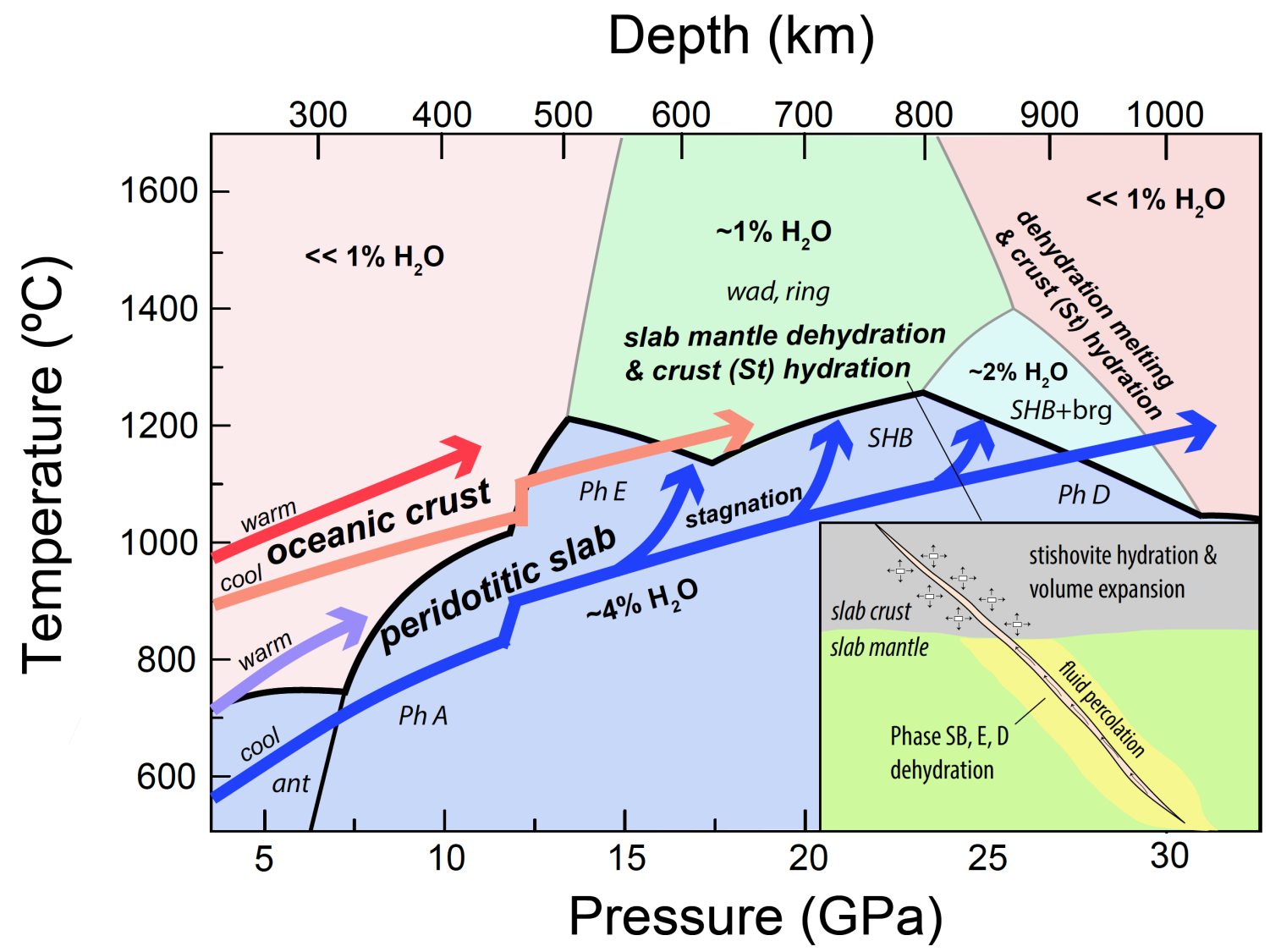

Extended Data Fig. 3 | Pressure-temperature diagram showing phase relations for watersaturated peridotite ${ }^{32,33,37}$. Phase labels designate generalized regions of stable hydrous magnesian silicates: ant=antigorite; $\mathrm{PhA}=$ phase $\mathrm{A} ; \mathrm{PhE}=$ phase $\mathrm{E} ; \mathrm{PhD}=$ phase $\mathrm{D}$; $\mathrm{SHB}=$ superhydrous phase $\mathrm{B}$; wad=wadsleyite; ring=ringwoodite; brg=bridgmanite. Water contents of peridotite at saturation are from Komabayashi and Omori ${ }^{33}$. Average geotherms for cool and warm slabs are show for peridotite at the Moho (blue and purple arrows) and for the top of the oceanic crust (orange and red arrows) and are after Van Keken et al. ${ }^{31}$. The inset is taken from Fig. 4 in the main text and shows an idealized model of dehydration in the transition zone of serpentinized mantle along fractures and percolation of fluids into adjacent crust where stishovite hydration occurs. 

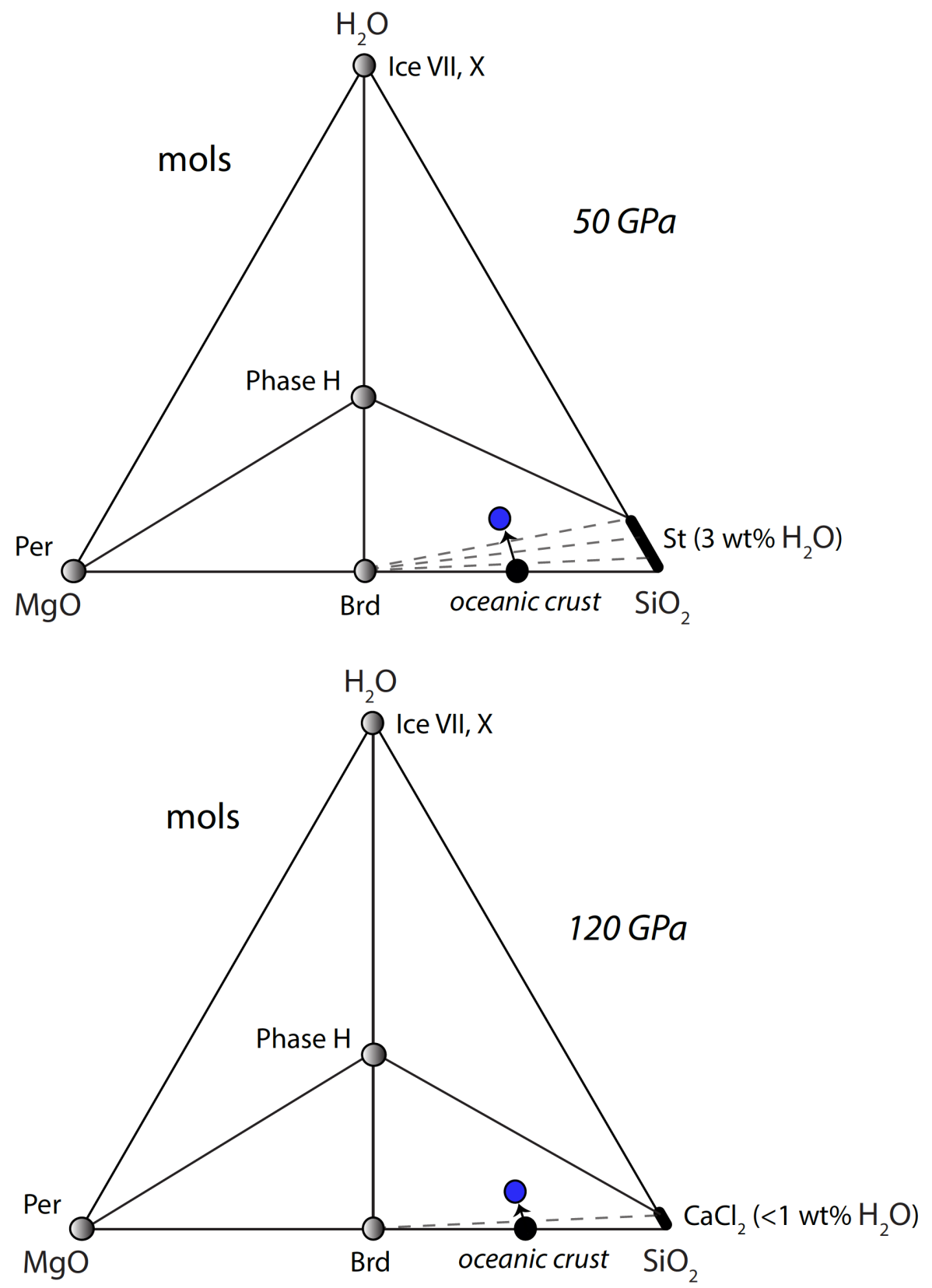

544 Extended Data Fig. 4 | Schematic compatibility diagrams in the system $\mathrm{MgO}-\mathrm{SiO}_{2}-\mathrm{H}_{2} \mathrm{O}$

545 (mols). The upper diagram illustrates phase compatibility at upper lower mantle conditions

$546(50 \mathrm{GPa})$ and the lower plot at conditions near the core-mantle boundary $(120 \mathrm{GPa})$. At 50

$547 \mathrm{GPa}$, stishovite can hold $\sim 3 \mathrm{wt} \%$ water whereas at $120 \mathrm{GPa}$ it holds $<1 \mathrm{wt} \%$ water.

548 Hydrous phases only crystallize in model hydrated oceanic crust (blue symbol) when bulk

549 compositions lie within the three-phase triangle, e.g. $\mathrm{SiO}_{2}-\mathrm{Phase} \mathrm{H}$ - bridgmanite (Brd). 


\section{Figures}
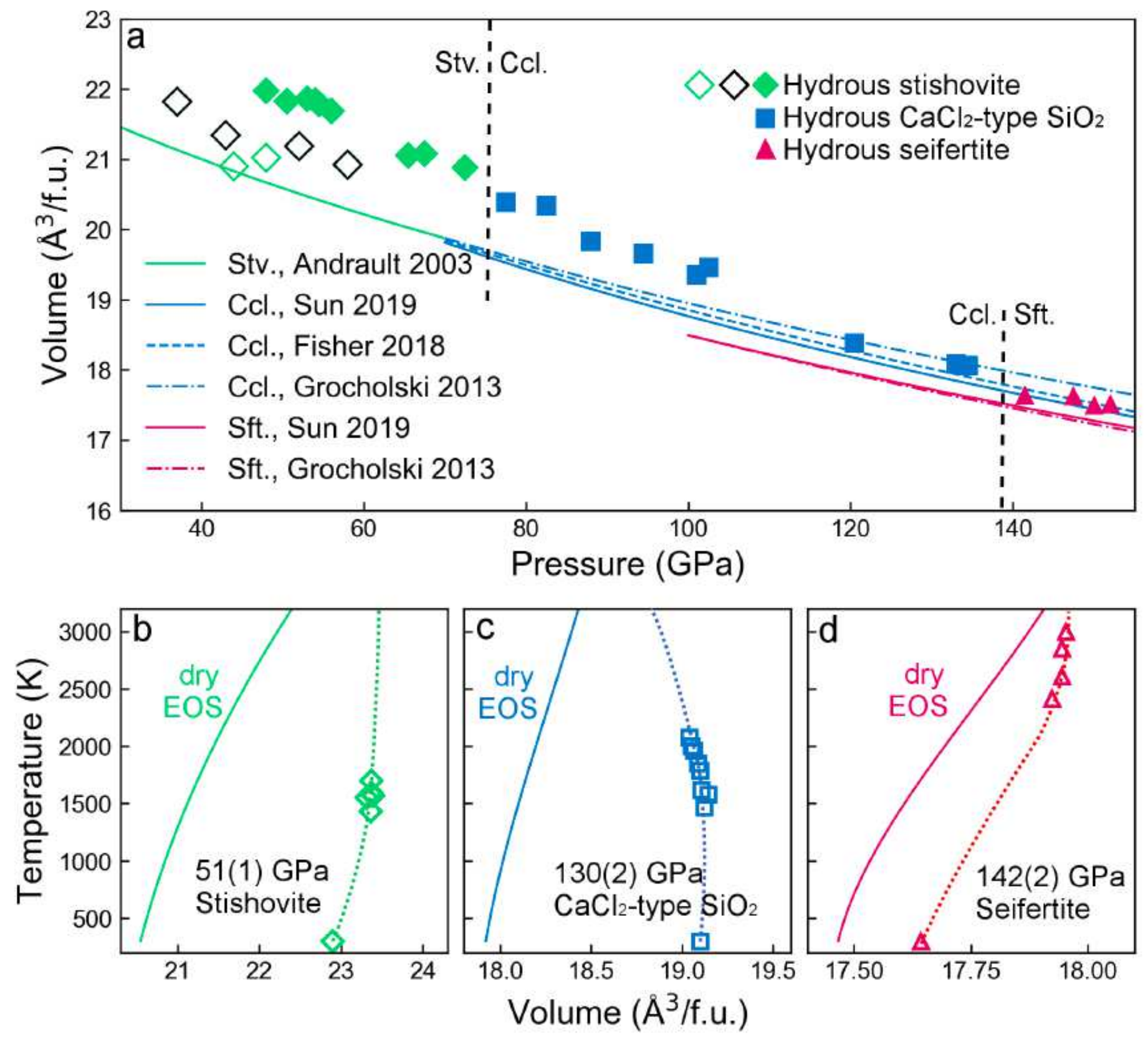

Figure 1

Measured unit cell volumes of hydrous high-pressure silica phases up to $152 \mathrm{GPa}$ and $3300 \mathrm{~K}$. (a) The solid and open symbols indicate silica volumes at water-saturated and water unsaturated, respectively, and are compared with the equations of state for anhydrous stishovite from Andrault et al.16, CaCl2-type silica and seifertite from Sun et al.12, Fischer et al.11 and Grocholski et al.17 (b-d) In situ high temperature volumes of stishovite (b), $\mathrm{CaCl}$-type $\mathrm{SiO} 2$ (c) and seifertite (d) compared with the thermal equations of states dry silica phases (solid curves, the literature data from Andrault et al.16 and Sun et al.12). Temperature uncertainties are generally less than $100 \mathrm{~K}$ below $2000 \mathrm{~K}$ and are up to $150 \mathrm{~K}$ at the highest temperatures. 

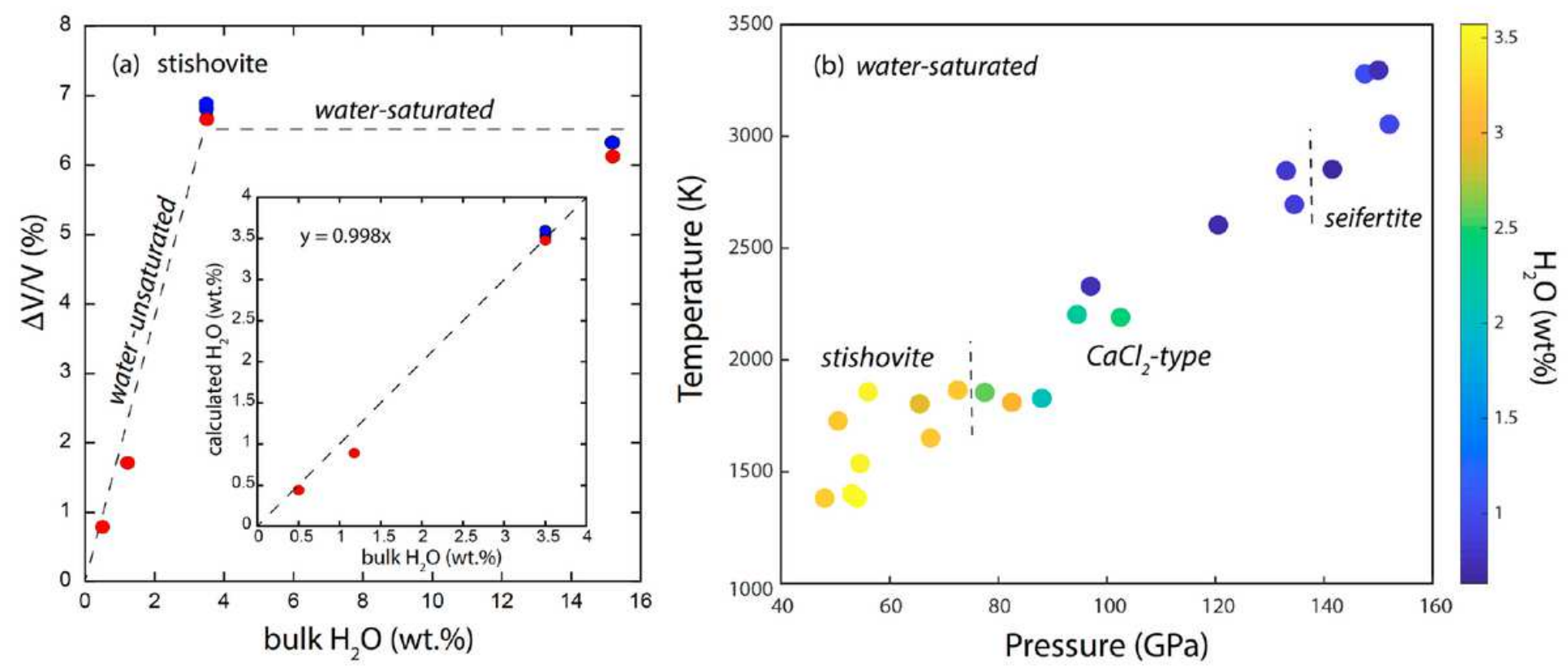

\section{Figure 2}

(a) Water contents in the bulk starting compositions versus measured unit cell volumes of hydrous stishovite relative to anhydrous stishovite (DV/V). Red symbols are experiments at $\sim 50 \pm 6 \mathrm{GPa}, 1800 \pm 70$ $\mathrm{K}$ and blue symbols are experiments at other pressures and temperatures. The inset shows the water contents in the bulk starting compositions versus the water contents of hydrous stishovite calculated using the Ice VII method described in the text. (b) Pressure temperature plot showing all experiments with 3.5 and $15.2 \mathrm{wt} \%$ water in the starting compositions (water-saturated). The symbols are colored according to the calculated water contents in the SiO2 polymorph according to the scale bar. 


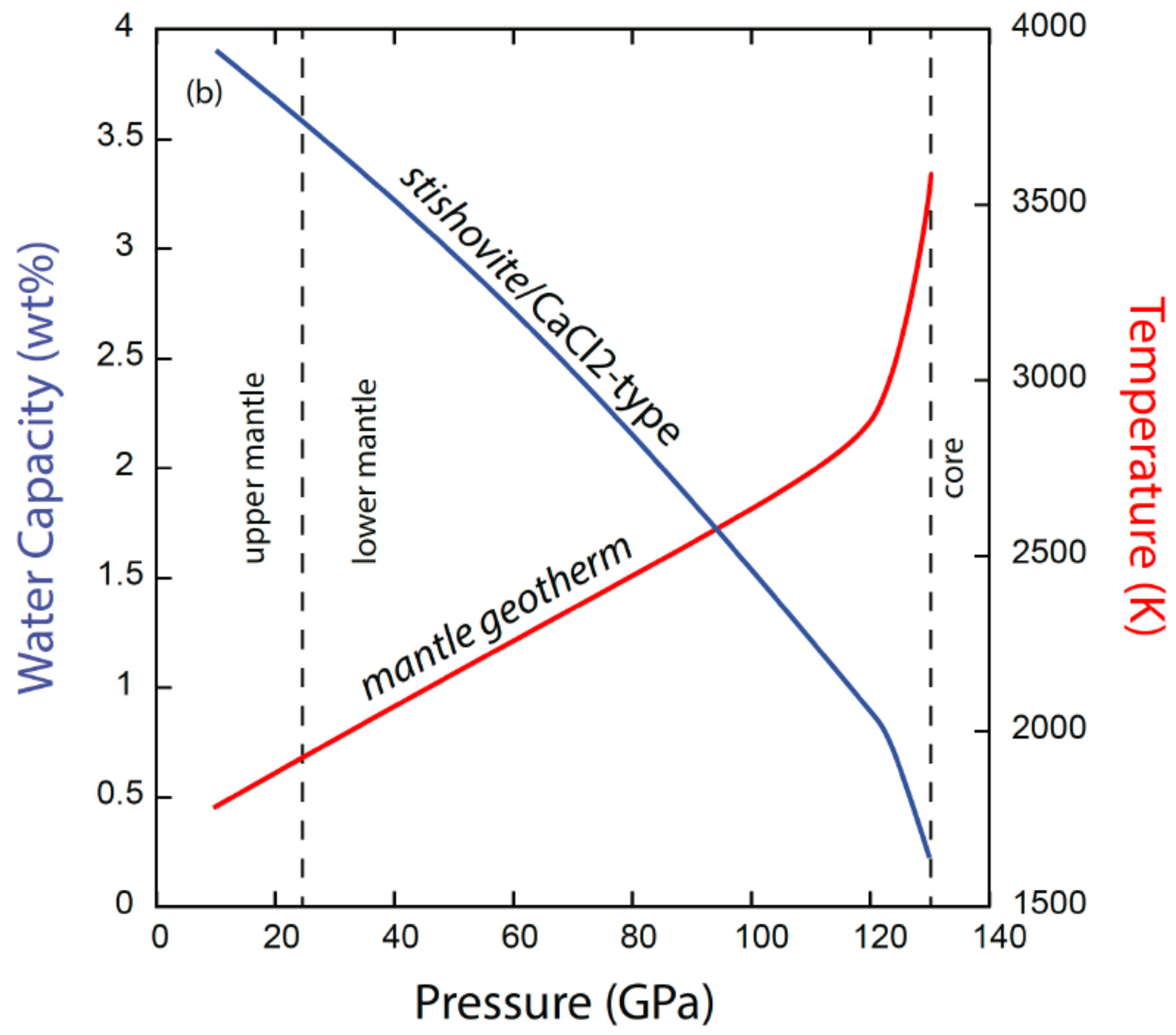

Figure 3

Modelled water capacity (blue curve) of stishovite and $\mathrm{CaCl}$-type SiO2 as a function of pressure along an idealized mantle geotherm (red curve22). The water capacity decreases continuously from $>3.5 \mathrm{wt} \%$ $\mathrm{H} 2 \mathrm{O}$ in the transition zone to $<1 \mathrm{wt} \%$ near the core mantle boundary. 


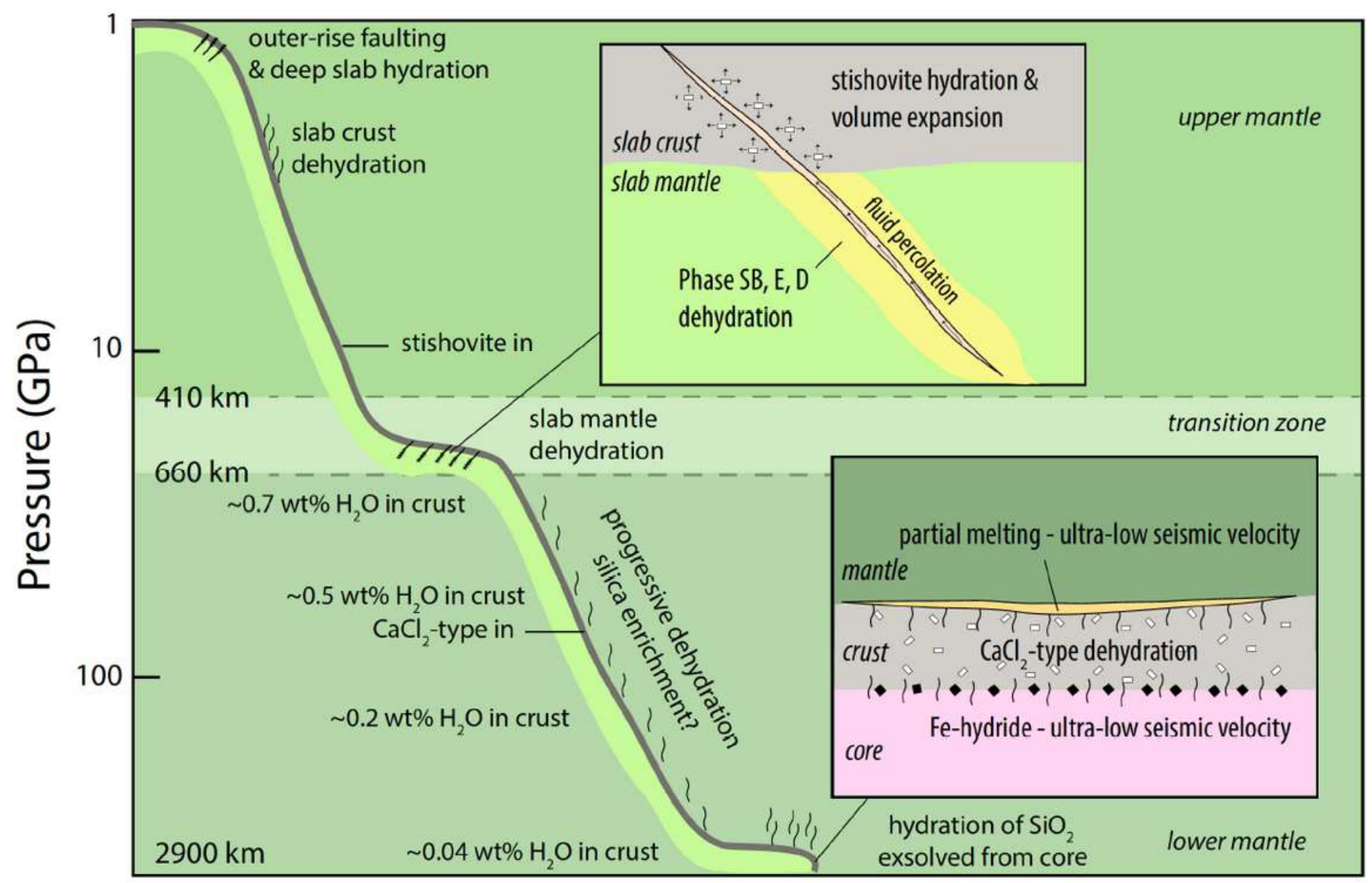

Figure 4

A schematic model for transport of water into the deep mantle in hydrous silica phases. Water is added to slab crust and mantle near the surface through interaction of seawater with the crust and through faults and cracks in the lithosphere formed by slab bending at the outer rise. Oceanic crust extensively dehydrates at $<200 \mathrm{~km}$ depth, but slab mantle can carry water into the transition zone in hydrous phases in cooler slabs. Dehydration of hydrous phases in slab mantle in the transition zone generates hydrous fluids that migrate along fractures to the oceanic crust where they hydrate stishovite ( 3.5 wt\% water). Stishovite transports water into the lower mantle where it converts to $\mathrm{CaCl} 2$-type $\mathrm{SiO} 2$, and the water capacity of these phases decreases continuously as the slab transits the lower mantle, potentially releasing hydrous fluids to the mantle that may cause melting and potentially enrich the mantle in silica. The rapid increase in temperature near the core mantle boundary may release a pulse of water that can induce partial melting50 and/or the crystallization of iron-hydride phases (e.g., FeO2Hx, FeH5)52-56 upon reaction with the metallic iron core, potentially leading to regions of ultra-low seismic velocity. Fluid release may also hydrate silica-rich domains at the core-mantle boundary formed through exsolution from the core. 